\title{
RURAL MEDICAL CARE IN INDIA
}

\author{
T. B. Patel, M.B., B.S., B.Sc., B.Hy.(Bom.), D.P.H.(Lond.) \\ Director of Public Health, Gujarat State, Ahmedabad, India
}

In India the responsibility for providing medical relief falls on both the State Governments and the local bodies. Usually the district hospitals are under the administrative control of State Governments while the dispensaries in the sub-divisions of the district are managed by local authorities. The latter receive a proportionate grant towards the maintenance of these dispensaries from the Government. In the past no systematic medical aid was provided for the villages. The local authorities and a few voluntary associations helped the neighbouring population in a haphazard manner. In many villages practitioners of the local indigenous medicine gave medical aid with traditional drugs while in others Registered Medical Practitioners (not qualified) rendered whatever medical relief they could in the absence of any regular medical service for the rural areas.

The population of India will, it is estimated, be $43 \mathrm{I}$ million by $196 \mathrm{r}$. Of this, about 330 million $(80 \%)$ reside in villages. The poor economic and social conditions of the village people, coupled with ignorance and difficult communications, afford a formidable barrier to progress. To provide a comprehensive medical and health service for this population is obviously a stupendous task and is closely linked with the living conditions of the people. During the last ten years determined efforts have been made in this direction. Comprehensive training programmes have been started to provide the manpower for the services in different fields of development. The position with regard to medical and auxiliary personnel is as follows:

\begin{tabular}{|c|c|c|}
\hline & I955-56 & $\begin{array}{l}\text { Number } \\
\text { Available } \\
\text { in } 1960-61\end{array}$ \\
\hline $\begin{array}{l}\text { Nurses (including nurse- } \\
\text { midwives) } \quad \ldots \\
\text { Auxiliary nurse-midwives/ }\end{array}$ & 22,000 & 31,000 \\
\hline $\begin{array}{ccc}\text { midwives } & . & \ldots \\
\text { Health visitors } & \ldots & \ldots \\
\text { Nurse dais/dais } & \ldots & \ldots\end{array}$ & $\begin{array}{r}26,000 \\
800 \\
6,000\end{array}$ & $\begin{array}{r}42,000 \\
2,500 \\
41,000\end{array}$ \\
\hline
\end{tabular}

AnNual Rate of Entry

\begin{tabular}{|c|c|c|}
\hline & $1955-56$ & $\begin{array}{c}\text { I960-6I } \\
\text { (estimated) }\end{array}$ \\
\hline $\begin{array}{l}\text { Nurses } \\
\text { Auxiliary }\end{array}$ nurse-midwives/ & 2,157 & 2,800 \\
\hline $\begin{array}{ccc}\text { midwives } & . & \ldots \\
\text { Nurse dais/dais } & \ldots & \ldots\end{array}$ & $\begin{array}{l}2,374 \\
\mathbf{I}, \mathbf{1} 5 \mathbf{1}\end{array}$ & $\begin{array}{l}4,000 \\
1,500\end{array}$ \\
\hline
\end{tabular}

In 195I there were 30 Medical Colleges in this country while in 1961 the number will be 55 ando the intake of students will increase from 2,500 to 5,000 . Similarly there were 65,000 qualifiedo medical men in 1956 . This number will reach the figure of 70,000 by 1961 , i.e. by the end of the Second Five Year Plan. The average population? served per doctor even then remains at $6,0 \notin 0$ which was also the proportion ten years ago, when the First Five Year Plan began. This is partly due to the high rate of growth of population in thiso country. Even though the average ratio of one doctor per 6,000 population may appear to be not unsatisfactory in the present stage of development of the country, in reality as the majority of doctors (about 60 to $70 \%$ ) prefer to practise in towns only, the rural areas are largely deprived of the medical services, and the ratio of doctors to population in 3 urban areas is about five to six times that of ruralo areas. The number of hospitals and dispensaries 3 . which was 8,600 in $195 \mathrm{I}$ will have increased to 12,000 at the end of 1960 . Similarly during the same period the number of beds will have in-o creased from II3,000 to I60,000.

The Government also embarked upon an ambitious plan to bring about an all-round improvement in the life of the village people and to raise their standard of living by means of what is $N$ known as the Community Development Programme. The basic idea underlying this programme aims at securing a co-ordinated develop-o ment of the rural life as a whole, by fighting disease, ignorance and poverty through one ${ }^{-}$ agency on a common platform, as all these three ${ }^{0}$ form a vicious circle. For implementing this 
programme the rural areas have been covered in a planned manner with development units called National Extension Services Blocks. Each National Extension Services Block (now called Stage I Block) consists of about Ioo villages with a population of 66,000 . It provides service in different fields of development like agriculture, village industries, education and basic health services like the provision of a safe water supply, sanitary conveniences and establishment of one Primary Health Centre per Block.

The idea of the Primary Health Centre first originated in the recommendations of the Health Survey and Development Committee appointed by the Government of India in 1946 . It envisaged provision of both medical relief and preventive health services including maternal and child health to the rural areas in an integrated manner.

In countries which are industrially underdeveloped, where the rural population lives in very poor economic conditions, and the State resources are limited, the pattern of health services has to be such as to avoid the overlapping of services and to economize manpower and materials. In this context the Primary Health Centre appears to be the most suitable unit of medical care for the rural population to satisfy the basic needs of the people and provide them with essential minimum services.

The Medical and Health Care Panel of the Planning Commission of the Government of India has also recommended the establishment of the Primary Health Centre as the smallest unit for bringing comprehensive health services to the rural areas, keeping in mind the financial resources, the limited training facilities and the availability of medical and para-medical personnel in the country. These centres undertake integrated medical care as envisaged by the World Health Organization Expert Committee, which defined 'Medical Care' as ' a programme of services that should make available to individuals and thereby to the community all facilities of medical and allied sciences, necessary to promote and maintain health of mind and body. This programme should take into account the physical, social and family environments with a view to the prevention of disease, restoration of health and alleviation of disability'.

By the end of the year 1960, 2,800 Primary Health Centres will have been opened in the country, each catering for a population of about 66,000 . It is proposed to cover the whole rural population by opening 2,200 more Primary Health Centres during the third Five Year Plan.

Each Primary Health Centre has three subcentres. The minimum staff at the main centre consists of:

I Medical Officer
I Compounder

I Public Health Nurse or Lady Health Visitor

I Auxiliary Nurse-Midwife or Midwife

I Health Visitor

2 Attendants

3 Nurse-Midwives, one located at each of the three sub-centres, which are situated so as to cover 20,000 population in the block population of 66,000 .

This staff is recommended in addition to the staff that may be already existing in the block area.

At the main headquarter centre there is a dispensary and six-bedded accommodation of which four are maternity and two general beds, while facilities are also provided for holding antenatal, infant, pre-school child and family planning clinics.

The Primary Health Centres have the following important functions:

I. Medical Relief.

2. Maternity and Child Health including Family Planning.

3. Control of communicable diseases which includes a routine prophylactic immunization programme.

4. School health service.

5. Health education.

6. Environmental sanitation with emphasis on improving the sanitation of villages by provision of latrines and proper disposal of excreta and refuse and ensuring protected water supply.

7. Collection and maintenance of vital statistics.

The Primary Health Centre is a fruitful instrument for bringing all health services to the community, some of which are given right in the homes-of the people. Its functions include the maintenance, promotion and protection of health of all members of the society. However, special attention is given to pregnant women, infants and pre-school children in view of their vulnerable condition. Food supplements such as skimmilk, vitamins, etc., reach the nursing mothers and children through the centres. These centres receive valuable assistance in the form of equipment, drugs and diet supplements from international agencies like the United Nations International Children's Emergency Fund, which also provides motor transport suitable for village conditions for the use of the staff.

The development of Primary Health Centres as rural units to provide efficient medical care, in an integrated manner, to the village people has many interesting features. For the first time now qualified medical graduates have been able to give efficient medical services to large parts of the rural areas where there were no facilities at all for such services in the recent past. Similarly services 
pertaining to maternity and child care as well as home nursing were unknown in the rural areas. With the establishment of Primary Health Centres such services have become an important feature. The trained staff of qualified health visitors and nurse-midwives regularly visit villages and serve the rural population by giving advice on ante-natal, infant and child care, on personal hygiene and also by providing nursing aid where necessary. This staff are given a refresher course in midwifery and paediatric procedures and reorientation training to suit rural conditions, with special bias on the preventive side, before they are posted to work in rural areas.

Another important aspect of the Primary Health Centre has been that it provides services entirely free to all the persons in need of it, irrespective of their economic conditions. The doctors as well as the nurse-midwives are not allowed any kind of private practice and have to work full-time. As the services provided by the staff are multifarious, the staff naturally remain extremely busy. It is also true that the existing staff with one doctor find it extremely difficult to look after the whole of the 66,000 population effectively and it has been suggested in some quarters that it would have been better if such services were concentrated in a smaller area to function in an intensified manner, rather than spreading them out in wider areas covering 66,000 population. In this connection it may be stated that one cannot afford to allow large masses of people in villages to go without any type of service facilities at the cost of a few getting most of the benefits and enjoying all the services. Hence the accepted policy of Government has been to provide the services to the greatest number even though in the beginning they may be less satisfactory. At the same time steps are being taken to remedy this situation by appointing one more medical officer per centre where one can be procured. During the Third Five Year Plan the nursing personnel will also be strengthened and clerical aid will be provided to relieve the technical personnel to enable them to devote more time to their professional duties. It is also intended to reduce the population served by a Primary Health Centre to 30,000 and later on as para-medical personnel become available this number will be reduced still further to 10,000. In certain States where adequate finance and personnel are available, Primary Health Centres catering for a population of 20,000 have been established under the State Schemes.

In the establishment of these centres one encounters several difficulties in view of the fact that many of them are located in the interior villages with no proper communications. Besides, en- vironmental conditions are poor, social amenities are not found and accommodation for staff is $\frac{\varrho}{2}$ either not available or is inadequate. Gradually these conditions are being improved byc providing better amenities by building quarters for $\Rightarrow$ staff as well as for the Centre and by improving the environmental sanitation of the villages. Ato the same time the emoluments of the staff are also음 increased to make them more attractive for rurals services.

As already stated the Primary Health Centre forms a pivotal basic medical service in the villages. Complicated cases from these centres. are referred to the next stage of the medical $\vec{\omega}$ service, namely ' referral hospitals', which areo provided with diagnostic X-ray and laboratoryo facilities as well as institutional paediatric treat- 3 ment facilities. These hospitals undertake routine specialist services. One such hospital with a bedif strength of 50 caters for about five to six Primary? Health Centres in the area. These are opened in each district in a planned manner. Due to $\infty$ financial stringency the progress in this respect is $\mathrm{O}$ rather slow. For higher specialized services cases are referred to the District Hospitals which are being improved for conducting such work.

Closely associated with rural medical care isำ the problem of communicable diseases contrgl $\overrightarrow{-}$ which takes up a good deal of the time of the medical personnel in the rural areas. Measurs. on a large scale are taken to bring down the in-O cidence of such diseases by concerted preventive action.

The Planning Commission of the Government of India in their draft outline indicated that during $\mathrm{D}$ the Third Five Year Plan, greater emphasis will $\vec{\circ}$ be placed on the prevention and eradication of 3 communicable diseases and in dealing with the diseases such as tuberculosis, and leprosy, public? health control measures being given top priority as음 against the provision of facilities for institutional care. National campaigns undertaken in this $\frac{3}{3}$ regard, such as a national malaria eradication programme, a mass BCG vaccination and TB controlo programme, anti-filaria measures, leprosy control measures, etc. have yielded gratifying results in reducing the morbidity and mortality and thus $\frac{D}{2}$ alleviating sickness and suffering among the rural population. In fact the malaria control campaign ${ }_{\mathscr{O}}^{N}$ alone which was started in 1952-53 has reduced the fever cases from malaria which were about 80 은 million with 800,000 deaths in 1952 to ro million cases with about 100,000 deaths in 1957 and it would be about I million cases with 10,000 deaths at the end of 1960 . This has been of immense relief and benefit to a large mass of village people. + These preventive activities are to be integrated into -0 the normal functions of the Primary Health Centres. 